\title{
Validity of pediatric index of mortality 2 (PIM2) score in pediatric acute liver failure
}

\author{
Claire Elizabeth Matthews ${ }^{1}$, Chulananda Goonasekera ${ }^{2}$, Anil Dhawan ${ }^{2}$ and Akash Deep ${ }^{2^{*}}$
}

\section{Introduction}

Pediatric acute liver failure (PALF) is an aggressive clinical syndrome in which a previously healthy child rapidly loses hepatic function and can become critically ill within days $[1,2]$. The mortality rate has been reported as high as $70 \%$ without a liver transplant, which is the only curative treatment to date [3]. However, when the current criterion of an international normalized ratio of more than 4 for listing for transplantation is used, $10 \%$ who are listed spontaneously recover and another $10 \%$ die while waiting to be listed [4]. This has serious implications for scarce donor organs and the risk of subjecting a child to unnecessary transplantation, surgical complications, and lifelong immunosuppression. The underlying challenge is to identify early enough those with PALF for whom chances of survival without a transplant are null, so that these can be super-urgently listed. As such, early mortality prediction is as important as the criteria for listing for transplantation.

The goal of the present study was to investigate the prognostic accuracy of the commonly used mortality prediction score known as pediatric index of mortality 2 (PIM2). PIM2 uses 10 variables on admission to the pediatric intensive care unit (PICU) to assess risk of mortality and in the UK is used as a measure of the quality of service. All children who were admitted to the PICU at King's College Hospital between 2003 and 2013 and who had PALF as defined by the PALF study group [1] were entered into a database which records routinely collected data that included daily clinical, biochemical, and treatment variables. We compared PIM2 scores on admission to 28-day survival with or without transplantation. As this was a retrospective analysis of routinely collected anonymized data, ethical approval or informed consent was not required. This study has been registered as a service evaluation project at King's College Hospital.

\footnotetext{
* Correspondence: akash.deep@nhs.net

2King's College Hospital, Denmark Hill, London SE5 9RS, UK

Full list of author information is available at the end of the article
}

\section{Findings}

One hundred and three children (55 males; median age 2 years, age range 0 to 19 years) were included. Forty-three received a liver transplant; of these, five died (mortality of $11.6 \%$ ). Of the 60 who were not transplanted, 20 died (mortality of $33.3 \%$ ). A receiver operating characteristic (ROC) curve was developed by using the study population and their outcomes. An area under the curve (AUC) of more than 0.75 was considered clinically useful [5]. The AUC in transplanted children was 0.346 ( $95 \%$ confidence interval (CI) 0.000 to 0.671 ), suggesting that PIM2 is of absolutely no value in predicting mortality in transplanted children. In the non-transplanted group, the AUC of ROC was 0.712 ( $95 \%$ CI 0.561 to 0.864 ), which was not sensitive or specific enough to minimize the risk of wrong categorization for transplantation.

Thus, we conclude that PIM2 is not fit for use in PALF as it neither predicts mortality nor identifies children in need of liver transplantation. It may also bias the quality assessment of PICUs in liver centers. As such, the quest for a better predictive score in PALF continues.

\section{Abbreviations}

AUC: Area under the curve; Cl: Confidence interval; PALF: Pediatric acute liver failure; PICU: Pediatric intensive care unit; PIM2: Pediatric index of mortality 2; ROC: Receiver operating characteristic.

\section{Competing interests}

The authors declare that they have no competing interests.

\section{Authors' contributions}

CEM carried out the data collection, interpreted the results, and drafted the manuscript. CG analyzed the data and performed the statistical analysis. ADh revised the manuscript critically for intellectual content. ADe participated in the design of the study and helped to draft the manuscript. All authors read and approved the final manuscript.

\section{Acknowledgments}

The authors appreciate the help and support provided by all staff, PICU, King's College Hospital, London.

\section{Biomed Central}

(c) 2014 Matthews et al.; licensee BioMed Central Ltd. This is an Open Access article distributed under the terms of the Creative Commons Attribution License (http://creativecommons.org/licenses/by/4.0), which permits unrestricted use, distribution, and reproduction in any medium, provided the original work is properly credited. The Creative Commons Public Domain Dedication waiver (http://creativecommons.org/publicdomain/zero/1.0/) applies to the data made available in this article, unless otherwise stated. 


\section{Author details}

${ }^{1}$ St Thomas' Hospital, Westminster Bridge Road, London SE1 7EH, UK. 'King's

College Hospital, Denmark Hill, London SE5 9RS, UK.

\section{Published online: 02 December 2014}

\section{References}

1. Squires RH Jr, Shneider BL, Bucuvalas J, Alonso E, Sokol RJ, Narkewicz MR,

Dhawan A, Rosenthal P, Rodriguez-Baez N, Murray KF, Horslen S, Martin MG,

Lopez MJ, Soriano H, McGuire BM, Jonas MM, Yazigi N, Shepherd RW,

Schwarz K, Lobritto S, Thomas DW, Lavine JE, Karpen S, Ng V, Kelly D,

Simonds N, Hynan LS: Acute liver failure in children: the first 348 patients in the pediatric acute liver failure study group. J Pediatr 2006, 148:652-658.

2. Sass DA, Shakil AO: Fulminant hepatic failure. Liver Transp/ 2005, 11:594-605.

3. Bansal S, Dhawan A: Acute liver failure. Indian J Pediatr 2006, 73:931-934

4. Shanmugam NP, Dhawan A: Selection criteria for liver transplantation in paediatric acute liver failure: the saga continues. Pediatr Transplant 2011, 15:5-6.

5. Zweig MH, Campbell G: Receiver-operating characteristic (ROC) plots: a fundamental evaluation tool in clinical medicine. Clin Chem 1993, 39:561-577.

\section{doi:10.1186/s13054-014-0665-z}

Cite this article as: Matthews et al:: Validity of pediatric index of mortality 2 (PIM2) score in pediatric acute liver failure. Critical Care 2014 18:665. 